\title{
MAĞCAN CUMABAY VE DÖNEMININ DIĞER ŞAIRLERINDE MiLLi üLKü
}

The National ldeal on Mağcan Cumabay and Other Poets of His Time

\section{Ospanova Akhur ABDUJAPARKIZI}

\section{ÖZ}

Makalede Kazak şiirinde Türkçülük ve Kazak ulusal kimliğinin ortaya çıkışı, Mağcan Cumabay'ın şiirlerindeki milli amaç, milli gayelerin tarihî sosyal temeli, XX. yüzyıl başlarında "Alaș" idealine bağlı diğer aydınların görüşlerindeki benzerlik ve paralellik çerçevesinde araştırılmıştır. Mağcan ve dönemindeki şairlerin Kazaklık bilincini şiirlerinde işlemeleri, aralarındaki benzer veya ortak imajlar, modern şiire katkıları gibi konular üzerinde durulmuştur.

Anahtar Sözcükler: Modern Kazak şiiri, Mağcan Cubabayoğlu (Jumabayulı), Alaş milli hareketi, Alaşçı şairler ve yazarlar, milli edebiyat, Kazak şiirinde milli ülkü.

\section{ABSTRACT}

In the article the national purpose, historical and sociological bases in Mağcan Cumabay's poems is studied as a part of similarities and differences in other intellectuals' opinions who are devoted to "Alaş" idea in the beginning of XX-th century.

Key Words: Modern Kazak poetry, Mağcan Cumabay (Jumabayulı), Alaş national movement, poets and writers in Alaş, national literature

\section{GíRiş}

Mağcan Cumabayoğlu'nun şiirlerinde Türkçülük teması, devamlı işlenen bir konu hâline gelerek, genel bir bütünlüğe sahip olmuştur. Onun bu konuları ele almasını Jusupbek Aymavıtov: "Mağcan çocukluğunda doğduğu yerlerde eğitim almaya başlamış, büyüdükten sonra dışarılara giderek, Ufa'daki Tatar medresesi “Galiye"de okumuştur.' Mağcan'ın ikinci talim-terbiye gördüğü yer işte burasıdır. Galiye Medresesi'nin hocaları Mısır'da, İstanbul'da eğitim görmüş Tatar aydınları idi. İslam terbiyesiyle yetişmiş, Müslümanlık, Türkçülük sevgisi taşıyan Tatar hocalar, öğrencilerini de bu ruhla terbiye etmişlerdi. Milliyetçilik, Türkçülük, dahası İslamcılık bayrağını taşıyarak, Galiye Medresesi, kendi döneminde Kazak, Tatar, Başkurt gibi halkların gençlerine birçok duyguları aşılayarak Rusya'nın boyunduruğu altındaki Türk evlatlarını bilinçlendirerek, Çar'ın baskıcı siyasetine karşı koymayı planlamıştır. Rusya'ya tâbi olan milletlerin bu tür uyanışı ve bu tür duyguları, elbette, hayatın ortaya koyduğu bir gerçek idi. Tarih bilgisi ile millî şuuru

"El-Farabi Kazak Milli Üniversitesi, Filoloji Fakültesi, Kazak Edebiyatı Bölümü PhD (Doktora) öğrencisi. Almaata, Kazakistan.

'Galiye [Aliye] Medresesi: Medine ve Kahire'de dinî eğitim almış Ziya Kemali (1873-1942) tarafindan 1906'da Ufa'da kurulan, dönemin en ileri medreselerinden biridir. Burada okuyan Tatar, Başkurt, Kazak ve diğer Türk halklarından birçok öğrenci, memleketlerinin fikir, siyaset ve edebiyat hayatında önemli rol oynamışlardır. 
güçlü olan şairin Oral tauvı (Ural dağı), Alıstağı bauırıma (Uzaktaki kardeşime), Tez baram (Hemen giderim), Türkistan, Turan'ın bir bauında” (Turan'ın bir yanında) vd. şiirleri, milli şiirimizde Türkçülük konusunun ilk defa ele alınarak işlendiği harika eserlerdir." (Amantay 2010: 159)

Kazak aydınlanma dönemi şiirlerinin birbirinden ayrılmayacak ortak yanları tarihî geçmişe duyulan özlem, halkı uykudan uyandırma gibi konulardı. Bunu Mağcan Cumabayoğlu Alka adlı şiirsel seslenişinde "Amacımız, halkı bilinçlendirmek, uyanması gereken günün geldiğini hatırlatmaktı" diye açıklar. "Edebiyatımızda bu "Uyan”² feryadı, halkın geçmiş günlerini onların hafızasında canlandırmaya başlamıştı. Geçmişi hatırlatmadan maksat, geçmiş devri tekrar yaşatmak ve geri getirmek değil; genç yaşlarından itibaren insanların yüreğine ümit vermekti. Bu amaçla geçmiş (tarih) edebî eserlere konu olmaya başlamıştı. (K,amzabekulı 1997: 260)

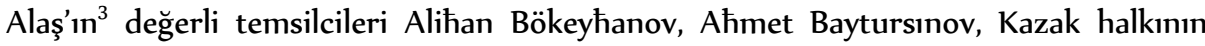
önemli şairi Mağcan'ın edebî mirası hakkında derin ve aydınlatıcı eserler yayımlamışlardır. XIX. yüzyılın sonunda Kazak edebiyatının daha önce görülmemiş zirvelerine yükselen Abay geleneği, realist, edebî düşünce dünyası, kendisinden sonraki millî söz sanatının amacını, şeklini kesinkes belirleyip ortaya koymuştur. Abay'dan sonra, Kazak edebiyatı realist özelliklere sahip olmuş ve yeni bir yönde gelişmeye başlamıştır.

XX. yüzyıl Kazak edebiyatının ilk yirmi yılında Şekerim [Şah Kerim] Kudayberdiyev, Mağcan Cumabay, Aћmet Baytursınov, Jüsipbek Aymavıtov, Mirjakıp Dulatov [Miryakup Devletov]'un eserleri çok dikkat çekicidir. Mirjakıp'ın Uyan Kazak kitabı, Kalın elim, Kazağım ("Kalabalık halkım, Kazağım”) diye coşup, bağrı yanan Abay'ın yüreğinden gelen hüznün, kederinin âdeta devamı gibidir ve milletin cesaretini daha da kuvvetlendirmeyi amaçlamış görünmektedir. Sultan Maћmut Toraygırov, Sabit Dönentayev, Muћametjan Seralin, Berniyaz Küleyev, Spandiyar [i̇sfendiyar] Köbeyev gibi büyük yeteneklerin şair coşkunluğuyla topluma hizmet ettikleri önemli günler, bu döneme denk gelmiştir. (Kazak Edebiyatınıñ Tarıћı 2006: 15-16)

Yeni realist ve milleti aydınlatma, bilinçlendirme amaçlı edebiyatın hususiyetleri ile yenilikçi nitelikleri, bilhassa XX. yüzyılın başlarındaki eserlerle edebî yayınlarda dikkat çekmektedir. Bu dönemdeki edebiyatın gelişmesinde öne çıkan temel iki hususiyeti ayrıntılı bir şekilde açıklamak gerekmektedir. Birincisi; XIX. yüzyılda, özellikle, asrın ikinci yarısındaki Kazak edebiyatında bir hayli yaygınlaşarak özel bir yere sahip olan Doğu edebiyatının kuvvetli tesiridir. Bunun derin geleneksel izleri zaten vardı. Bu şekilde dinî nitelikli edebiyatın yaygınlaşması, belli bir zirveye ulaşınca yavaşlamaya başlamıştır. Böylece Kitabi akındar (Kitabî şairler) diye adlandırılan güçlü bir tarz, kendine özgü yanlarıyla ortaya çıkmış ve yeni edebî süreçte özel bir yere sahip olarak, kendi kurallarıyla

\footnotetext{
2 “Uyan Kazak": Mirjakıp Dulatov (Mir Yakup Devletoğlu)'ın şiiir kitaplarından birinin adıdır.

${ }^{3}$ Alaş: Milli Kazak hareketinin adı. 1906'da Kazak milliyetçi aydınları "Kazak Anayasal Demokrat Partisi"ni kurmuş ve siyasî faaliyete başlamışlardı. 1917'de bir kongreyle bu partinin adı "AlaşOrda" olarak değiştirildi ve millî niteliği daha da belirgin hâle geldi.
} 
edebiyatta yer almıştır. Daha sonra edebiyatın gelişme süreci, yönü, başlıca temsilcilerinin görüşleri Batı, Rus kültürü ve yeni devrin "bilimsel" yeniliklerine, dünya görüşüne doğru kaymaya başlamış gibidir.

Mağcan Cumabay kendi makaleleriyle çevirilerinde ve ders kitaplarında, eğitim öğretim hakkındaki çalışmalarında, "bilim" dünyasını esas alarak bilime, Avrupa medeniyetine doğru yönelen tavrını dikkat çekici bir şekilde ortaya koyar. Mesela, Muћtar Avezo] “Mağcan'ı seviyorum, Avrupalılığını, parlak fikirlerini seviyorum. Kazak şairlerinin kara gübreli köyünde dünyaya gelerek, Avrupa'daki medeniyetle güzellik sarayına gidip güzeller güzeli Arka'nın kızını görüp onunla tanışmış gibi oluyorum. Mağcan, çok medeniyetli bir şair” derdi. Bu dönemler, Mağcan'ın Ufa'da, Ombı'da, Moskova'da eğitim gördüğü, N. Y. Bryusov'un onu "Kazakların Puşkin'i” diye adlandırıldığı dönemdir. (Mağcan 1996: 407)

Mağcan'ın dünya görüşü ile manevî dünyasında bu yönünün ortaya çıkması, belirginleşmesi doğal bir süreçti. Bu dönemdeki Kazak aydınları ile milliyetçi şahsiyetler ve aydın topluluğunun önemli temsilcilerinin hemen hemen hepsi Avrupa tarzı eğitim alıp, Rusya'nın meslekî bilim merkezlerinde okuyanlar idi. Yüzyılın başlarındaki siyasî faaliyetlere aktif bir şekilde katılanlar da onlardı. Alaş Orda'nın batısında da, doğusunda da fikir hareketlerine onlar önderlik ederdi.

Kazak kültür hayatının gelişmesinin bu döneminde, edebiyatın yeni bir şekli olan gazetecilik de gelişti ve milliyetçilik ülküsünü temel alan millî edebiyat da olgunlaşmaya başladı. İşte bu sözünü ettiğimiz ikinci hususiyettir. Bu hususiyet, eskiden beri halka yakın bir sanat olarak sayıla gelen şiir ve destanlarda, olabildiğince net görülmektedir. Ozanlık geleneği devam edip daha da şekillenip gelişirken bir yandan da devrin şartlarına uygun, zamanın getirdiği yeni dönem şiiri, çar çabuk kendi yerini bulmuştur. Köteş, Şal Akın şiirlerinde örnekleri ortaya çıkmaya başlayan ozanlık geleneği, Abay geleneğiyle birlikte daha da yükselerek, yeni bir ekol oluşturmuştur. Yani, o dönemlerde şairlik geleneği yeni ekol içinde biçimlenerek canlanmıştır. Şiir dünyasında büyük değişiklikler meydana gelmiştir. Şairler, bir taraftan ozan şiirin temel şekillerini, edebî söz sanatlarını daha da olgunlaştırarak devam ettirmişlerse, diğer yandan çağdaş dünya görüşünden kaynaklanan yenilikleri de bunlara ekleyerek şiir sanatını birlikte geliştirmişlerdir. Bu yeni oluşumda Avrupa ve Rus edebiyatının edebî etkileri daha fazla dikkati çekmiştir. Böylece Batı ile Doğu'dan eşit olarak etkilenen Kazak şiiri, kendi millî kimliğini, dil özelliklerini de korumakla beraber, dünya şiirine doğru yol almıştır.

Abay geleneği, Abay ekolü, Kazak şairlerine yol gösteren, onların yolunu aydınlatan fener gibidir. Akademisyen Zeki Ahmetov'un Poeziya Şını; Dânâlık (Şiir Sanatının Zirvesi; Bilgelik), Abay'dın Akındık Elemi (Abay'ın Şairlik Dünyası) adlı kitapları, Abay geleneğinin bu başlangıç noktalarını teorik açıdan derin bir şekilde yorumlayarak, ortaya koymuştur. Zeki Ahmetov, büyük düşünür Abay'ın geleneğini devam ettiren, geliştiren edebiyatçılar arasında büyük Kazak şahsiyetleri Şekerim, Mağcan Cumabay, Aћmet Baytursınov ve Mirjakıp Dulatov gibi şairleri-yazarları zikrederek, onların eserlerini incelemiş, Kazak edebiyatı tarihindeki ıslahatçılığa dayanan şairlik okulunun özelliğini belirlemiştir. Böylece, şairlik sanatının millî temelini sağlamlaştıran unsurun, geleneksel yolun 
kuvvetli gücü olduğunu ortaya koyduktan sonra Abay bilgeliği hakkındaki çeşitli düşüncelerin her birini, onun şairlik sanatından, şairlik ustalığından yola çıkarak açıklar. Zeki Ahmetov'un 2002 yılında yayımlanan, Abay'ın şairlik ferasetini inceleyen Poeziya Şını; Dânâlık adlı kitabı, bu büyük yetenek sahibinin kalıcılığını ispatlayan bir çalışma olmuştur. (Abay Şığarmalarının... 2004: 86)

XX. asın başlarındaki edebiyatta önemli eserleri yayımlanan, medeniyetin gelişmesine bir hayli katkıda bulunan Ğumar [Ömer] Karaş'a ve onun eserlerine uzun süre değer verilmemiştir. $\mathrm{O}$, adı anılmış olsa da, yeterince incelenmemiş, araştırılmamış yetenekli sanatçılardan biridir. Ğumar [Ömer] Karaş, on-on beş yıllık edebî faaliyeti sırasında, Kazak edebiyatı tarihinde bugüne dek çok kıymet verilen Kazak ozanlarının iki ciltlik antolojisini, kendinin beş şiir kitabını, birkaç araştırması ve makalelerini yayımlatmayı başarmıştır. "Bökeylikten" takma adıyla, halk ağzından derlediği edebi eserleri Şağır yaki Kazak Akındarını Bastı Jıları (Şair veya Kazak Şairlerinin Önemli Manzumeleri”, 1910) ve Köksilder (Avcı Kartallar, 1910) antolojileri, edebî mirasın esas hazinesi, kaynağı gibidir. Bu külliyatlar, söz tahlilini yapmada, şiirin tarihini araştırmada ya da birçok edebi yorum meselelerini araştııp öğrenmede önemli kaynak eserlerdir. Bununla birlikte Ğumar Karaş'ın Bala Tulpar (Yavru Tulpar, 1911), Karlğaş̧ (Kırlangıç, 1911), Tumış̧ (Akraba, 1911), Ağa Tulpar (Büyük Tulpar, 1914), Turımtay (Bozdoğan, 1918) adlı arka arkaya yayımlanan beş şiir kitabı, şairin ilham dolu yıllarına işaret ettiği gibi, şiirleri de, konuları, şekilleri, şiir sanatı bakımından taşıdıkları özellikleriyle yeni dönem edebiyatına uzanmaktadır. Alaş siyasetinden çok umutlu olan, müjdeli şiirlerini topluma armağan eden şairlerle birlikte (Mağjan Cumabay, Sultanmahmut Toraygırov, Jusipbek Aymavitov vd.) Ğumar Karaş da Alaşı ın yiğitlerine çeşitli manzumelerini ithaf etmiştir. Yurttaşlık bilinci ve felsefi düşüncelerle zengin şiirlerinde genellikle eğitimcilik, milliyetçilik, milli kurtuluş konularını ele almıştır.

Daha sonra XX. yüzyıl edebiyatının önemli ve kişilikleriyle ön plana çıkan yazarlarının, yetenekli şahsiyetlerin kitapları da, bu dönemde epeyce yayımlanmıştır: Meşhur Jusip [Yusuf] Köbeyev'in 1907 yilında Kazan'da basılan üç eseri; Hal-ahval, Tirlikte Köp Jasağandıktan Körgen Bir Tamaşamız (Uzun Yıllar Yaşayınca, Gördüğümüz Bir Eğlence), Sarıarka Kimdiki Ekendigi (Sarıarka'nın Kime Ait Olduğu Hakkında) okuyucularıyla buluşmuştur. Şairin hürriyet konusunda açıkça söylediği fikirleri ve 1905 yılındaki Rus devriminin etkisiyle dile getirdiği düşünceleri yüzünden, onun üç kitabını yayımlayan basım evine on iki bin som para cezası verilmiştir.

1915 yilında Sabit Dönentayev'in Ufa'da Uak-Tüyek (Ufak-tefek) adında ilk külliyatı yayımlanmışıı. Saken Seyfullin'in “Ötken Künder” (Geçmiş Günler, 1914), Mağcan Cumabay'ın Şolpan (1912), Nurjan Nauşabaev'ın Alaş (1910), Mirjakıp Dulatov'un Oyan Kazak! (Uyan Kazak! 1909), Beket Ötetileuov'un Jiyğan-Tergen (Birikim, 1914) adlı külliyatları ile yukarıda adı geçen diğer kitaplar, bu dönemdeki edebiyatın havasını ve yönünü, oldukça geniş biçimde gözler önüne serebilmektedir.

Sadece yirmi yedi yıl yaşamasına rağmen, kendini edebiyata adadığı on yıl kadar bir zaman içerisinde, oldukça önemli ve büyük edebî miras bırakan Sultanmahmut Toraygırov'un (1893-1920) bu dönemdeki eserleri, hayatının o özel dönemini yansıtır. Şairin 
kaleme aldığı ilk kitabı, kendisi vefat ettikten sonra 1922 yılında basılmıştır. Bu döneme kadar eserleri, gazete ve dergiler aracılığıyla halkın içinde ağızdan ağıza yayılmıştır. "Tüsümde” (Rüyamda, Aykap, 1913, №ı), “Bular kim?” (Bunlar kim?), “Kımız”, “ìtarşıga” (Dalkavuğa, Aykap, 1913, №9, №18, №20) “Şakird oyı” (Şakirdin düşüncesi), “Jas jürek” (Genç yürek, Sarıarka gazetesi, 1917, №19, №15), “Nege jasaymın” (Niye yaşayayım, Abay dergisi, 1918, №3), “Altı ayak” (Aykap, 1915, №3). Daha başka şiirleri de yayımlanmıştır. Kazak ${ }^{4}$ gazetesinin yayımlanmasına sevinerek tebrik için yazdığı “Mıne, Alakay!” (isşte, Yaşasın!, Kazak, 1913, 1 Nayrız, №4) şiiri, onun milliyetçilik düşüncesini ve bakış açısını açıkça ifade etmekteydi. "Karanğı tünek tünde edi, kara Kazak balası" (Karanlık gecenin içindeydi, kara Kazak balası), "yirminci asır başında” parlak günler gelip "neşredildi Alaş!” diye, gelecek günlere umutla bakarak çoşmuştu. Sultanmahmut'un kaleme aldığı "Alaş marşı" (1917) milliyetçilik fikrinin yüksek sesi olarak heyecan uyandırmıştı. Genel olarak, şairin bütün eserleri aslında XX. yüzyılın başlarındaki yirmi yıl içerisinde kaleme alındı ve bunlar, o dönemdeki Kazak edebiyatının durumunu, imkânlarını ve yönünü açıkça gösterebildi. “Adaskan Ömür” (Kaybolmuş Hayat), Kazak edebiyatında manzume tarzının, daima canlı bir ruha sahip örnekleri arasında yerini aldı. "Kedey” (Yoksul) adlı manzumesi de edebî ve tarihî açıdan anlamlı bir eserdir. Manzum yazılmış ilk Kazak romanı olan Kamar Suluv (Güzel Kamer) ise, realist Kazak edebiyatının ilk dönemlerindeki büyük yayıncılık olaylarından biridir. Şairin, yaratııılık hayatının başlıca üç dönemini; 1907-1911 yıllarını içerisine alan çıraklık dönemini, 1912-1913 yıllarında Aykap' da ${ }^{5}$ çalıştığı dönemlerdeki şiirlerini ve 1917-1918 yılları arasında Semey'deki yazarlık hayatını, ayrıntılı araştıran akademisyen Serik Kıyrabayev, onun bu dönemde alev gibi yanan şairlik karakterinin, kesin olarak istikrara kavuştuğu kanaatindedir.

S. Toraygırov'un şairliği, yeni Kazak şiirinin aydınlık sayfalarına dönüşerek, güçlü, etkili, hüzünlü ve nağmeli bir yurttaşlık şiiri olarak kendine has anlaşılır, uygun, güzel tavrıyla kolay hissedilip, kabul edilmiştir. Bazı şiirleri, Abay ahenginin emsallerine tekrar canlılık kattıysa, bazı şiirleri, şahit olduğu kargaşalı, çetin dönemi tam olarak tasvir etmiştir. "Sarıarkanın janbırı" (Sarıarka'nın yağmuru) 1917 yılındaki Kazakların hayatını bütün derinliğiyle yansıtmaktadır:

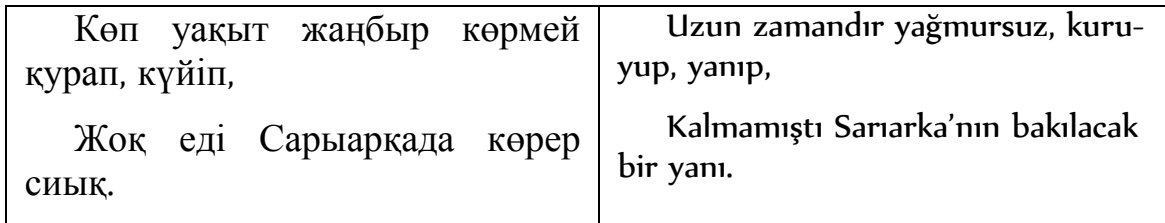

\footnotetext{
${ }^{4}$ Kazak Gazetesi: 1913-1914 yılları arasında Orenburg'ta Ahmet Baytursunov ve Mirjakıp Dulatov'un yayımladığı toplam 264 sayı çıkan, milli ülküyü benimsemiş Kazak gazetesi.

${ }^{5}$ Aykap: $1911-1918$ yılları arasında Troysk'ta Muhammedcan Seralin tarafindan toplam 88 sayı yayımlanan Kazak dergisi.
} 


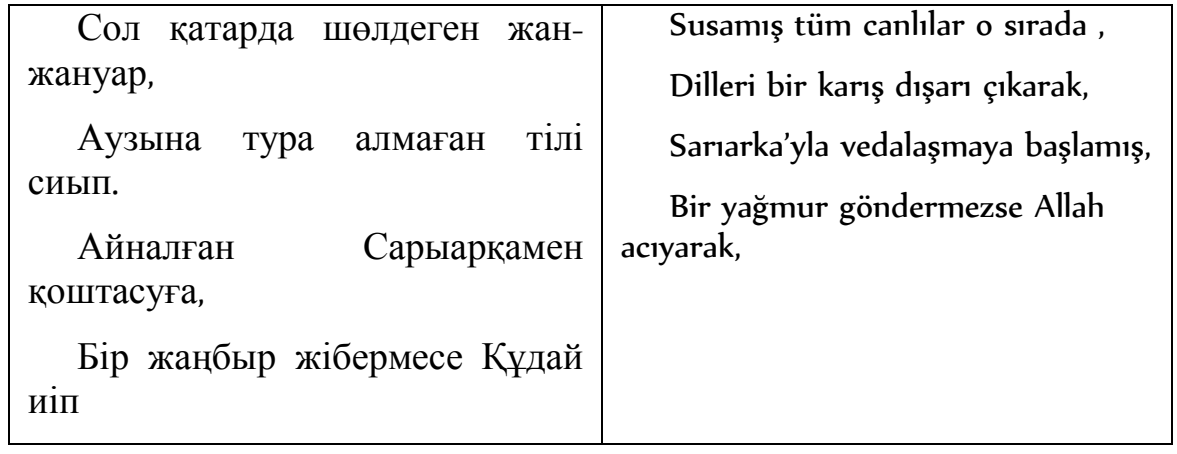

diye başlayan şiiri umutla, hayalle doludur ve şair Sarıarka'nın yağmurunu özgürlüğün esintisi gibi hissetmektedir.

\begin{tabular}{|cr|l|}
\hline $\begin{array}{c}\text { Көрсетсін қара шекпен } \\
\text { еккен ісін, }\end{array}$ & $\begin{array}{c}\text { Göstersin kara cepken (Rus köylüleri) } \\
\text { yaptığını, } \\
\begin{array}{c}\text { Қиналып } \\
\text { жеккен күшін, }\end{array}\end{array}$ & $\begin{array}{l}\text { Zorlayıp merhametsizce uyguladıkları } \\
\text { gücü }\end{array}$ \\
\hline
\end{tabular}

diye başlayan sadece altı bölümlük "Itarşığa" (Dalkavuğa) şiirinde de, o zamanın çizgileri çok belirgin bir şekilde görülmektedir. (Sultanmahmut 1993: 6, 120, 78)

Sultanmahmut Torayğırov: “1) Kazak edebiyatı tarihindeki ilk roman yazarlarından biridir. ilk manzum romanı yazmıştır; 2) Kazak edebiyatında mevzusuz (süjesiz, tahkiyesiz), felsefi-lirik manzume tarzını oluşturmuştur; 3) Kazak edebiyatında gerçek anlamda gazete makaleleri yazarlarından birisidir”. Bütün bunlar, şairlik hayatı XX. yüzyılın başlarındaki on-on beş yıla denk gelen Sultanmahmut Toraygırov'un zengin ve üstün yeteneğinin, başarısının değerlendirilmesiyle elde edilen sonuçlardır. (Beysenbay 1993: 136)

XX. yüzyılın başlarındaki edebiyatın başlıca temsilcilerinden biri olan Berniyaz Kuleyev (1899-1923) kendine özgü anlatım tarzıyla birlikte, Kazak şiir tarihindeki yerini alarak, Abay şairlik okulunun yıldızı ve genç şairi olarak kalacaktır. Yirmi beş yaşına girer girmez acı bir kaza geçirerek umutları yıkan, büyük bir üzüntüye sebep olan şair Berniyaz'ın şiirinin havasında, üslup, ahenk ve ölçülerinde, Abay şiir sanatının sesi ve ahengi hâkimdir. Abay'ın şiir örneklerine "Bostandık kününde” (Özgürlük gününde), söz sanatına "Jırla da zarla könilim" (Söyle ve derdini dök gönlüm) şiirlerinde oldukça yaklaşmış, zamanın talebine uygun yeni ruhta, hemen geleneğe dönüşen şiirler yazmıştır. $O$ dönemde gerçek ilham sahibi şairlerden biri de Berniyaz Kuleyev idi. O, kendi zamanının sözünü söyleyebilmiş ve Abay gibi büyük şahsiyetin okulunu daha da sağlamlaştırarak, canlandırmıştır. 
Ele alınan dönemde manzum hikâye tarzının gelişmesine katkıda bulunan eserler de yazılmıştır: Muhametjan Seralin'in realist, romantik nitelikli Topjargan (Önder, 1898 yılında yazılmış, 1900 yılında kitap olarak yayımlanmış), "Gülhaşima” (1901 yılında yazılmış, 1903'te basılmış) manzumeleri; Sultanmahmut Toraygırov'un güçlü yurtseverlik ruhuyla realist içerikli "Tanıstıru” (Tanıştırma, 1918), "Adaskan Ömür” (Kaybolmuş Hayat, 1918), "Kedey" (Yoksul, 1919), tamamı ele geçmeyen "Kaygı” (1919), tamamlanmamış "Aytıs" (1919) gibi manzumeleri; lğılman Şörekov'un tarihî realist tiplerle dolu olan şiirsel "isatay-Mahambet" (daha sonra, 1924 yılında "Sayle" dergisinin 4. sayısında yayımlandı) manzumesi; Şedi Jengirov'un Doğu ahengini daha da derinleştirerek nazireciliği devam ettiren "Nazım Çehar deruyiş" (1913), Rus-Kazak tarihi ilişkilerinin geçmişini temel alan "Resey patşalığında Romanov nesilinen hükmıranlık kılğan patşalardı๊ tarıћtarı

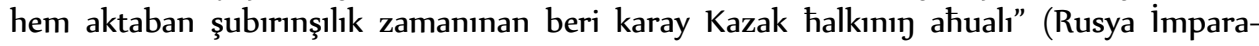
torluğunda Romanov Neslinden Hükümdarlık Eden Çarların Tarihleri ve Aktaban Şubırınşılık ${ }^{6}$ zamanından bu yana Kazak halkının ahvali, 19ı2) destanları ve daha başka eserler, bu dönemde epik tarzda bin bir çeşit, şiir sanatı özelliklerinin oldukça geliştiğini göstermektedir.

Manzume tarzının realist, tarihî, yurtsever, felsefi niteliği millî ruhu belirginleştirerek, güçlendirmiştir. Şairler yaşamın akışına, günlük sosyal olaylara katkıda bulunarak, düşüncelerini ifade ediş tarzlarıyla (farklı üsluplarla), şiirin ebedîliğini kat kat artırmıştır. Yurtseverlik bilinci, gazetecilik teması, söz ustalığıyla zirvelere çıkmıştır. Şiirin alışılmış ritmi, hece yapısı, hızlı bir şekilde yenilenerek, canlanarak, şeklî değişimler geçirmiştir:

\begin{tabular}{|l|l|}
\hline Жарық күн туды, & Aydınlık gün doğdu, \\
Жер жүзін жуды & Yer yüzünü yıkadı \\
Көктен нұрлар төгіліп. & Gökten nurlar dökülüp, \\
Ежелгі, ескі, & Ezeli, eski (şeyler), \\
Ортадан кетті, & Ortalıktan kayboldu, \\
Етек-жеңі сөгіліп. & Eteği-kolu sökülüp. \\
& Berdiyaz Kuleyev, \\
& Bostandık küninde \\
\hline
\end{tabular}

${ }^{6}$ Aktaban Şubırınşılık: "Yayın ayakla koşmaktan taban kemiğinin açığa çıkması” anlamına gelen, XVII-XVIII. asırlarda özellikle 1723-30 yılları arasında Kalmuk (Moğol) istilası döneminde Kazak halkının çektiği acıları, zorlukları anlatan bir deyim. 
Иесі болса дағы алтын тақтың,

Көнеді бенде ісіне жалғыз хақтың.

Тағдырға мойын сұнып, елден безіп,

Мен жүрмін ортасында бөтенжаттын

Сары қазы, сары қымыз тамағы боп,

Жүргенде жастары біздің жақтың,

Өлшеулі ет, қара шайды тамақ қылып,

Өткізіп жүрмін уақытын жастық шақтың.

$* * *$

Я, Алла! Жеткізе гөр мұратыма,

Рахаты бар деуші еді мехнаттың.
Sahibi olsa dahi altın tahtın,

Razı olur kul, Hakkın yazdığına

Kadere boyun eğip, yurttan gidip,

Yaşıyorum yabancıların arasında.

Sarı kazı ${ }^{7}$, sarı kımız aşı olup

Bizim gençler şu hayatı yaşarken,

Ölçülü et, sütsüz çayı aş ederek ni.

Geçiriyorum şu gençlik dönemi-

$* * *$

Ya Allah! Ulaștırıver muradıma

Derler; bir ferahı vardır her sıkıntının.

Saken Seyfullin

"Kazak Sayağl"

\begin{tabular}{|c|c|}
\hline$* * *$ & $* * *$ \\
\hline $\begin{array}{l}\text { Қарасаң } \quad \text { сонда } \\
\text { арасынан, }\end{array}$ & $\begin{array}{l}\text { Baktığında o sırada Kazakların } \\
\text { içindeki, }\end{array}$ \\
\hline $\begin{array}{l}\text { Ойнаған жалаңаяқ баласына, } \\
\text { Кетеді іш елжіреп, жанып, } \\
\text { күйіп, }\end{array}$ & $\begin{array}{l}\text { Yalın ayak oynayan balasına, } \\
\text { içine hüzün çöker, kaygılanır, üzü- } \\
\text { lürsün, }\end{array}$ \\
\hline
\end{tabular}

${ }^{7}$ Kazı: Atın kaburğa etlerinden alınan etin tuz ve biberle terbiye edilip barsağa doldurulmasıyla yapılan bir nevi pastırma, Kazak millî yiyeceği. 


\begin{tabular}{|l|l|l|}
\hline $\begin{array}{c}\text { Көңілдің тұ3 сепкендей } \\
\text { жарасына. }\end{array}$ & $\begin{array}{l}\text { Tuz ekmiş gibi gönül yarasına. } \\
\text { (Mağcan Cumabay } \\
\end{array}$ \\
& & \\
& & \\
& & \\
\end{tabular}

Bu şiirler muhtevası açısından tam o dönemin problemlerini ele alan eserler oldukları gibi şiir sanatı ve biçimleri açısından da, eski ozanların deyişlerinden uzaklaşarak değişmeye başlayan Kazak şiirini de göstermektedirler. Kısa şiirleri, yurtseverlik bilinci taşıyan siyasî konulu şiirlerin bir birinden güzel örneklerini, aşk şiirinin eşsiz parçalarını, şairlerin ifade biçimlerini güzelleştirerek anlamı derinleştirmelerini, zamanın Kazak şiirine getirdiği bir farklılık olarak değerlendirilebilir. Şekil ve kalıp arayışları, karmaşık istiareler (metaforlar), yurtseverlik düşüncesinin belirginliği, o dönemlerdeki Kazak şiirini, alışılagelmiş destanlarla şïlerden ayırarak, farklı bir yere koymaktaydı. Şiirlerdeki sosyal-dramatik konular, tartışma hızı gelişmeye devam etmiştir. Belli bir olayı konu eden, kısa şiirler, süjesiz manzum şiirler ortaya çıkmıştır. Bunların hepsi, Kazak şiirinin kısa dönem zarfında değişerek yeniden canlanmasını, gelişme sürecini gözler önüne sermektedir. XX. yüzyıl başlarında şairlik yeteneği, yeni soluklu, sosyal konulu şiirler önemli yer tutarak, aydınlatma, öğüt verme, halkçılık niteliklerini daha da derinleştirme Kazak şiirinde devam etmiştir. Alaş yanlısı şairlerin sesleri daha gür bir şekilde duyulmaya başlamıştır. Yüzyılın başlarında temellerini Abay'ın attığı, realist şiir örneklerinin daha da yaygınlaşarak gelişmeye devam ettiğini, manzum eserlerinin içeriklerinin zenginleştiğini, şiir formlarının değiştiğini, milli hususiyetlerin daha da yaygın hâle geldiğini söyleyebiliriz.

Neticede, XX. asrın başlarında, millî kurtuluş ülküsünün hızla gelişmeye başlamasıyla birlikte temeli oluşan önemli değişimler; edebî bilinç alanındaki ani farklılıklar; beklenmedik, işlenmemiş konular, yeni yazılı edebiyatımızda yeni biçimlerin çı̆̆ır açmasına kendince tesir etmiştir. Söz sanatının ve özellikle şiirin geçmişi, halk hayatının çeşitli merhaleleriyle sıkı ilişki içinde olmuştur. Kazak şiirinin milletin kaderiyle hayatını özellikle ele almasının yanı sıra, buna uygun olarak kendisinin de kalıplaşma, güçlenme, yükselme veya gerileme dönemleri geçirdiği aşikâdır. Edebiyatın milli vasıfları, onun sadece göze çarpan, sadece dış imgeleriyle değil, asırlarca yönü değişmeden devam ede gelen iç yapısı ve mahiyeti itibarıyla gizemli olan tabiatından da anlaşılmalıdır.

\section{KAYNAKÇA}

Abay Şığarmalarının Eki Tomdık Tolık Jinağı (2004), 1. c., Almatı, Kazak Universiteti Baspası.

Amantay (2010) Şarip, “Söz Öneri Jane Ulttık Ruh”, Astana, Pedagogika Press Baspası.

Beysenbay (1993) Kenjebayev, XX. Ğasır Basındağı Edebiyet, Almatı. “Bilim” Baspası.

Ķamzabekulı (1997) D., Ruћaniyat, Almatı, Bilim Baspası.

Kazak Edebiyetinin Tariћı (2006), 6 cilt; “XX. Ğasırdın Basındağı Kazak Edebiyeti (1900-1917)”, Almatı, Atamura Baspası.

Mağjan (1996) Cumabay, Şığarmaları, 3 ciltlik, 3. c., Almatı, Bilim Baspası. 
Sultanmahmut (1993) Torayğırov, Eki Tomdık Şığarmalar Jinağı, 1. c., Almatı, Atamura Baspası XX. Ğasırdağı Kazak Edebiyeti, Oktiyabr Aldındağı Kezeñ (1983). Ğılım Baspası, 312 c. 